\title{
Maximum power control for photovoltaic system using intelligent strategies
}

\author{
Mohammed Slimi, Abdelkrim Boucheta, Bousmaha Bouchiba \\ Department of Electrical Engineering, University of Tahri Mohammed BP417, Algeria
}

\begin{tabular}{l}
\hline \hline Article Info \\
\hline Article history: \\
Received Apr 20, 2018 \\
Revised Nov 5, 2018 \\
Accepted Dec 5, 2018 \\
\hline Keywords: \\
Converter \\
Fuzzy logic \\
Mamdani model \\
MPPT \\
P\&O \\
Photovoltaic \\
Takagi-Sugeno model \\
\hline
\end{tabular}

\begin{abstract}
The power supplied by photovoltaic DC-DC converter is affected by two factors, sun irradiance and temperature. Therefore, to improve the performance of the PV system; a mechanism to track the maximum power point (MPP) is required. Conventional maximum power point tracking approaches, such as observation and perturbation technique present some difficulties in identifying the true MPP. Therefore, intelligent systems including fuzzy logic controllers (FLC) are introduced for the maximum power point tracking system (MPPT). In this paper, we present a comparative study of the PV standalone system which is controlled by three techniques. The first one is conventional based on the observation and perturbation technique, the other are intelligent based on fuzzy logic according Mamdani and Takagi-Sugeno models. The investigations show that the fuzzy logic controllers provide the best results and Takagi-Sugeno model presents the lower overshoot value.
\end{abstract}

Copyright (c) 2019 Institute of Advanced Engineering and Science. All rights reserved.

\section{Corresponding Author:}

Mohammed. Slimi,

Department of Electrical Engineering,

Laboratory of Research Control, Analysis and Optimization of Electro-Energetic Systems,

University of Tahri Mohammed BP417, Bechar (08000), Algeria.

Email: mohammed.slimi213@gmail.com

\section{INTRODUCTION}

Solar energy is inexhaustible, free and clean and it is considered as the core of renewable energy (RE) in the recent times primarily because of running down of fossil fuels. Among various RE resources, photovoltaic (PV) system plays a very important role either in grid-connected or islanding configurations. However, the PV systems generate intermittent power under fluctuating weather which is the main issue that must be taken in consideration [1], [2]. The power-voltage and current-voltage characteristics are responsible for the power generated from the PV cell. Therefore, to work the PV generation at its peak; the MPPT mechanism is highly significant in PV system [3]-[6]. Numerous MPPT mechanisms have been introduced by many scholars since year 1960. Some well-known MMPT methods are incremental conductance (IC) method, perturb and observe (P\&O) method and constant voltage (CV) method [7]-[9]. The method of P\&O was extensively used due to its simple control method as well as the minimum number of its input parameters. However, the use of this algorithm leads to a loss in power due to an enormous oscillation in the area of maximum power point (MPP). Others, like IC methods have been proposed by some researchers [7], [8], which somehow could eliminate the oscillations in the area of the MPP. However, this kind of methods need good and accurate sensor to measure either voltage or current. Recently, the MPPT-based Artificial intelligence (AI) is widely used in PV converter with great dynamics and high effectiveness. Various intelligent methods including fuzzy logic and artificial neural network (ANN) have been mentioned in the literature. The fuzzy logic controllers are widely used for the MPP tracking [7]. They are independent of process model, which present an ability to apprehend the problems of nonlinearity and have robust performance to the atmospheric conditions changes. The two most important types of fuzzy inference method 
are Mamdani's fuzzy inference method and T-S method. In this study, the MPPT is developed using three different techniques to assess their performances. This paper is organized as follows. The description and modeling of the PV system is mentioned in section 2. MPPT based on Perturb and observe (P\&O) algorithm is described in section 3. MPPT based on fuzzy logic is explained in section 4 . The simulation and results analysis are discussed in section 5. Finally, the conclusion is exposed in section 6.

\section{DESCRIPTION AND MODELING OF THE PV SYSTEM}

The block diagram of the proposed standalone PV system as shown in Figure 1. The system consists of a PV array (BP Solar SX 150S), a MPPT controller combined to a DC- DC converter (Boost) and a load (resistance).

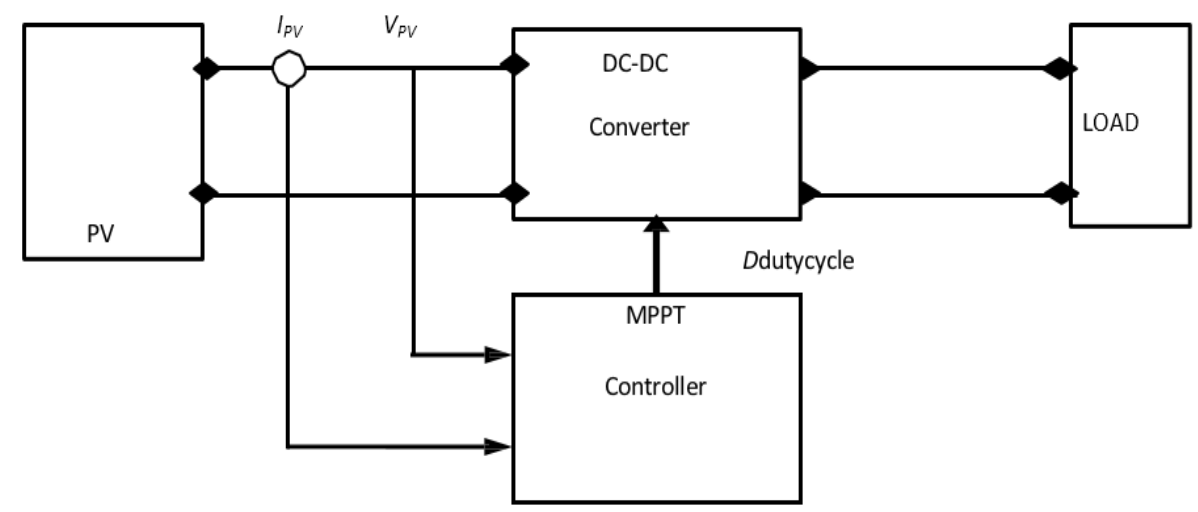

Figure 1. Block diagram of the global PV system

The G and T are in charge of the working point of PV system at the MPP [13], [14]. The cell current, I, which represent the mathematical model of the PV cell can be express as [15]:

$$
I=I_{p h}-I_{0}\left(e^{\left(\frac{q\left(V+I R_{s}\right.}{A \cdot K_{c} T}\right)}-1\right) \frac{V+I R_{s}}{R_{s h}}
$$

Where Iph is light-generated cell current $(A), I_{0}$ is cell reverse saturation current $(A), q$ is electronic charge, A is ideality factor, $\mathrm{Kc}$ is Boltzmann's constant, and $\mathrm{T}$ is cell temperature $(\mathrm{K})$. According to the equation above, the output power varies according to $\mathrm{G}$ (irradiance) and T. The mathematical model can be used to determine the cell output current. Figures below show the electrical characteristics under varying weather $\mathrm{G}$ and $\mathrm{T}$ of the BP Solar SX 150S according its characteristics as shows in Table 1.

Table 1. PV module characteristics

\begin{tabular}{cc}
\hline PV module & BP Solar SX 150S \\
\hline Maximum power (Pmax) & $150 \mathrm{~W}$ \\
Voltage at Pmax (Vmp) & $34.5 \mathrm{~V}$ \\
Current at Pmax (Imp) & $4.35 \mathrm{~A}$ \\
Open circuit voltage (Voc) & $43.5 \mathrm{~V}$ \\
Short circuit current (Isc) & $4.75 \mathrm{~A}$ \\
Temperature coefficient of Isc & $0.065 \pm 0.015 \% /{ }^{\circ} \mathrm{C}$ \\
Temperature coefficient of Voc & $-160 \pm 20 \mathrm{mV} /{ }^{\circ} \mathrm{C}$ \\
Temperature coefficient of power & $-0.5 \pm 0.05 \% /{ }^{\circ} \mathrm{C}$ \\
NOCT & $47 \pm 2{ }^{\circ} \mathrm{C}$ \\
\hline
\end{tabular}

Int J Pow Elec \& Dri Syst, Vol. 10, No. 1, March 2019: 423 - 432 
At constant temperature $25^{\circ} \mathrm{C}$ shows in Figure 3 and Figure 5, the increase in irradiance value leads to an increase in maximum power and a minor increase in open circuit voltage, while the short circuit current varies significantly. This implies that the optimal power generator is almost proportional to the illumination. With a constant irradiation is shown in Figure 2 and Figure 4, the open circuit voltage decreases notably with increasing temperature and the maximum power too. For this case, we can deduce that the voltage changes significantly while the current remains constant. To get a maximum power, it is important to work in the area of MPP of the PV generator. In the next sections, we will compare conventional and intelligent strategies which track the MPP of the PV generator.

\section{BP SX 150S Photovoltaic Module I-V}

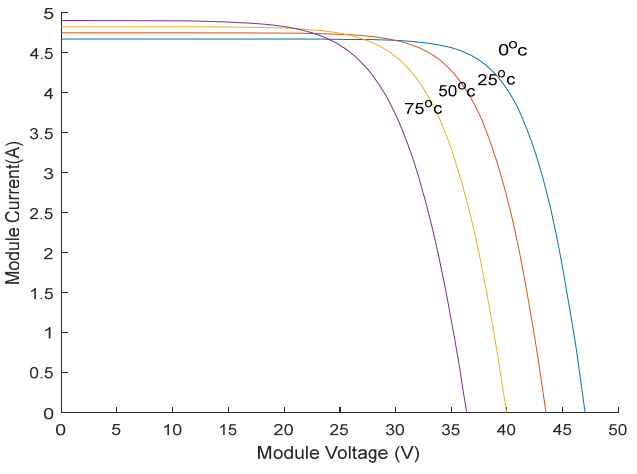

Figure 2. I-V curves at various temperatures

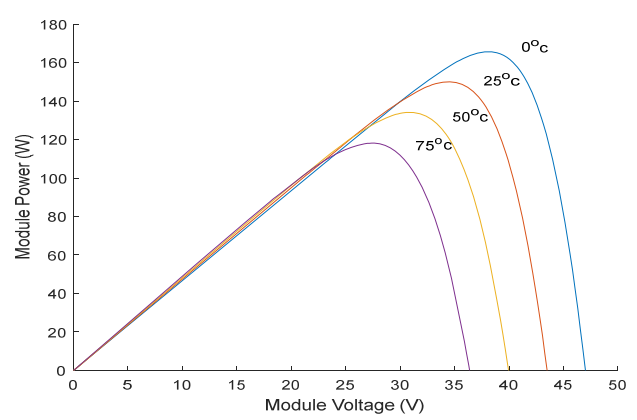

Figure 4. P-V curves at various temperatures

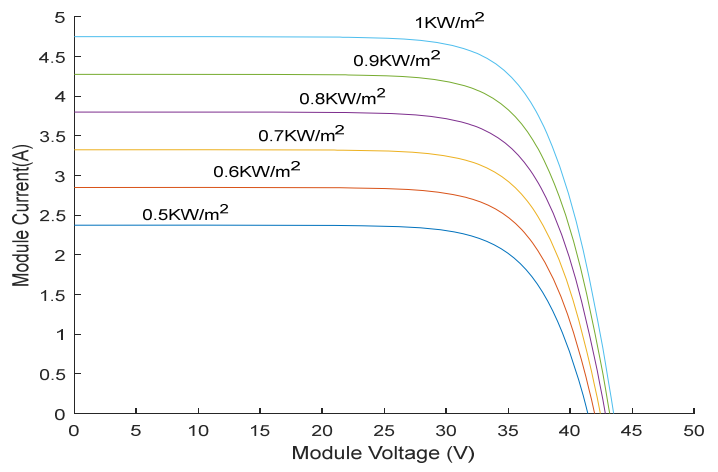

Figure 3. I-V curves at various radiations

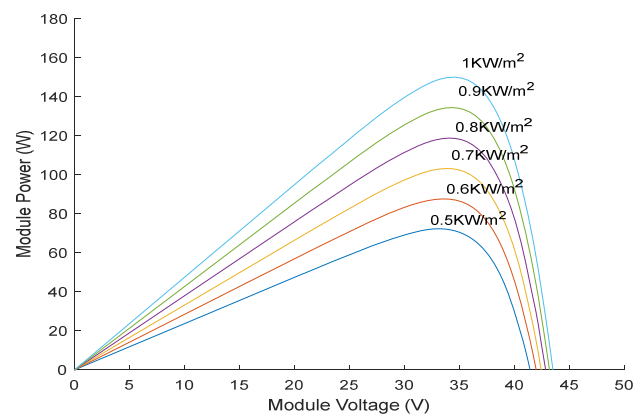

Figure 5. P-V curves at various radiations

\section{MPPT BASED ON P\&O ALGORITHM}

$\mathrm{P} \& \mathrm{O}$ algorithm are widely used in MPPT because of their simple structure and their few measured parameters which are required. As its name indicates, it is based on the system perturbation by increasing or decreasing of VPV, then observing the effect on the output power of the panel. If the current value of the power $\operatorname{PPV}(\mathrm{k})$ of the panel is greater than the previous value $\operatorname{PPV}(\mathrm{k}-1)$ then the direction of perturbation is maintained otherwise it is reversed. With this algorithm the operating voltage VPV is perturbed at each cycle of the MPPT. When the MPP is reached, VPV oscillates around the maximum power point which causes system power losses, depending on the step width of a simple perturbation. If the step width is large, the $\mathrm{P} \& \mathrm{O}$ algorithm will respond quickly to rapid changes in operating conditions with increasing oscillation around the MPP under stable or slowly changing conditions. If the step width is smaller the oscillation around the MPP will be reduced but the system will respond slowly to sudden changes in atmospheric conditions [16], [17]. 


\section{MPPT BASED ON FUZZY LOGIC}

Fuzzy logic controller (FLC) is a nonlinear control method. Hence, it can be easily applied for nonlinear characteristics of PV system to track maximum power point. FLC is operated using membership functions instead of mathematical model [13].

\subsection{Fuzzy MPPT based on mamdani's inference}

Conventional methods of tracking the optimal point of operation have shown their limits to sudden changes of weather and the load connected to the panel, several methods have emerged to try to alleviate these shortcomings and improve the operation of these generators. The approach of Artificial Intelligence in the case of fuzzy logic is implemented to improve control performance and the pursuit of maximum power point by simulation and modeling of a controller based on fuzzy logic [17]. The advent of microcontrollers has enabled the spread of fuzzy control in the pursuit of optimal point during the last decade. The fuzzy controller has the following three blocks: Fuzzification of input variables by using the trapezoidal functions, then these fuzzified variables are compared with pre-defined packages to determine the appropriate response. And finally, the defuzzification converts the obtained area according to fired rules to crisp value which controls the plant. Mamdani's fuzzy inference method is the most commonly seen fuzzy methodology. Mamdani's method was among the first control systems built using fuzzy set theory. It was proposed by Mamdani (1975) as an attempt to control a steam engine and boiler combination by synthesizing a set of linguistic control rules obtained from experienced human operators. Mamdani's effort was based on Zadeh's (1973) paper on fuzzy algorithms for complex systems and decision processes. In this work, each linguistic variable of the fuzzy MPPT controller has five linguistic values: NB (Negative Big), NS (Negative Small), Z (Zero Approximately), PS (Positive Small), PB (Positive Big). The two FLC input variables are the error E and change of error CE at sampled times $k$ defined by:

$$
\begin{aligned}
& E(k)=\frac{P(k)-P(k-1)}{V(k)-V(k-1)} \\
& C E(k)=E(k)-E(k-1)
\end{aligned}
$$

Where $\mathrm{P}(\mathrm{k})$ is the instantaneous power of the PV generator. The input $\mathrm{E}(\mathrm{k})$ shows if the load operation point at the instant $\mathrm{k}$ is located on the left or on the right of the maximum power point on the PV characteristic, while the input $\mathrm{CE}(\mathrm{k})$ expresses the moving direction of this point. The fuzzy inference is carried out by using Mamdani's inference shows in Table 2, and the defuzzification uses the centre of gravity to compute the output of this FLC which is the duty cycle:

$$
d \alpha=\frac{\sum_{j=1}^{n}\left(d \alpha_{j}\right)-d \alpha_{j}}{\sum_{j=1}^{n} \mu\left(d \alpha_{j}\right)}
$$

Table 2. Fuzzy rules table of mamdani's inference

\begin{tabular}{cccccc}
\hline E/CE & NB & NS & Z & PS & PB \\
\hline NB & PB & PB & PS & PB & PB \\
NS & PS & PS & PS & PS & PB \\
Z & NS & NS & Z & PS & PS \\
PS & NB & NS & NS & NS & NB \\
PB & NB & NB & NS & NB & NB \\
\hline
\end{tabular}

\subsection{Fuzzy MPPT based on takagi-sugeno's inference}

This method was introduced by Sugeno (1985). The main difference between Mamdani and Takagi Sugeno is that the TS output membership functions are either linear function or constant. Also the difference lies in the consequences of their fuzzy rules, and defuzzification procedures.

A typical rule in a Sugeno fuzzy model has the form :

IF Input $1=x$ AND Input $2=y$, THEN Output is $z=a x+b y+c$. 
For a zero-order Sugeno model, the output level $\mathrm{z}$ is a constant $(\mathrm{a}=\mathrm{b}=0)$. The output level zi of each rule is weighted by the firing strength wi of the rule. For example, for an AND rule with Input $1=x$ and Input $2=\mathrm{y}$, the firing strength is:

$$
w_{i}=\text { AndMethod }\left(F_{1}(x), F_{2}(y)\right)
$$

Where, $F 1,2(\cdot)$ are the membership functions for Inputs 1 and 2 . The final output of the system is the weighted average of all rule outputs, computed as (5):

$$
\text { Final output }=\frac{\sum_{i=1}^{N} w_{i} z_{i}}{\sum_{i=1}^{N} w_{i}}
$$

In this work, the fuzzy MPPT based on Sugeno's inference has been implemented according to the fuzzy rule table below.

Table 3. Fuzzy rules table of Sugeno's inference

\begin{tabular}{ccccc}
\hline E/CE & NB & NS & PS & PB \\
\hline NB & PB & PB & NB & NB \\
NS & PS & PS & NS & NS \\
PS & PS & PS & NS & NS \\
PB & NB & NS & PS & PB \\
\hline
\end{tabular}

The two inputs Error And change of error have the same membership functions as shown in Figure 6:

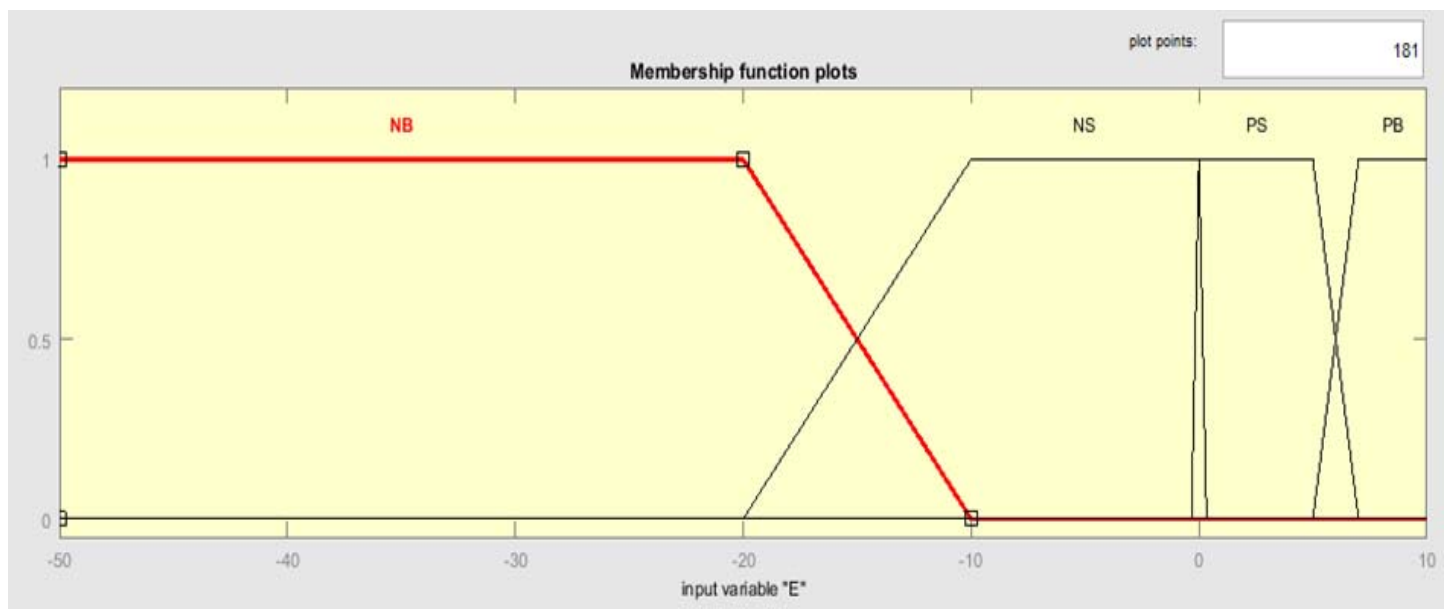

Figure 6. Input error and change of error membership functions

And the output's singletons are respectively as below: $\mathrm{NB}=-0.08, \mathrm{NS}=-0.04, \mathrm{PS}=1, \mathrm{~PB}=2$.

\section{SIMULATION AND RESULTS ANALYSIS}

BP Solar SX 150S PV module is chosen for the simulation which has the characteristics above.

The simulation has been done under Matlab/Simlink as shown in Figure 7:

The simulated system has four main blocks: the PV module (BP Solar SX 150S), the MPPT controller which is based on P\&O, Mamdani's, and sugeno's model at each simulation, PWM generator, and $\mathrm{DC}-\mathrm{DC}$ boost converter. The comparison is done under $\mathrm{G}=1000 \mathrm{KW} / \mathrm{m} 2$ and $\mathrm{T}=25^{\circ} \mathrm{C}$. 


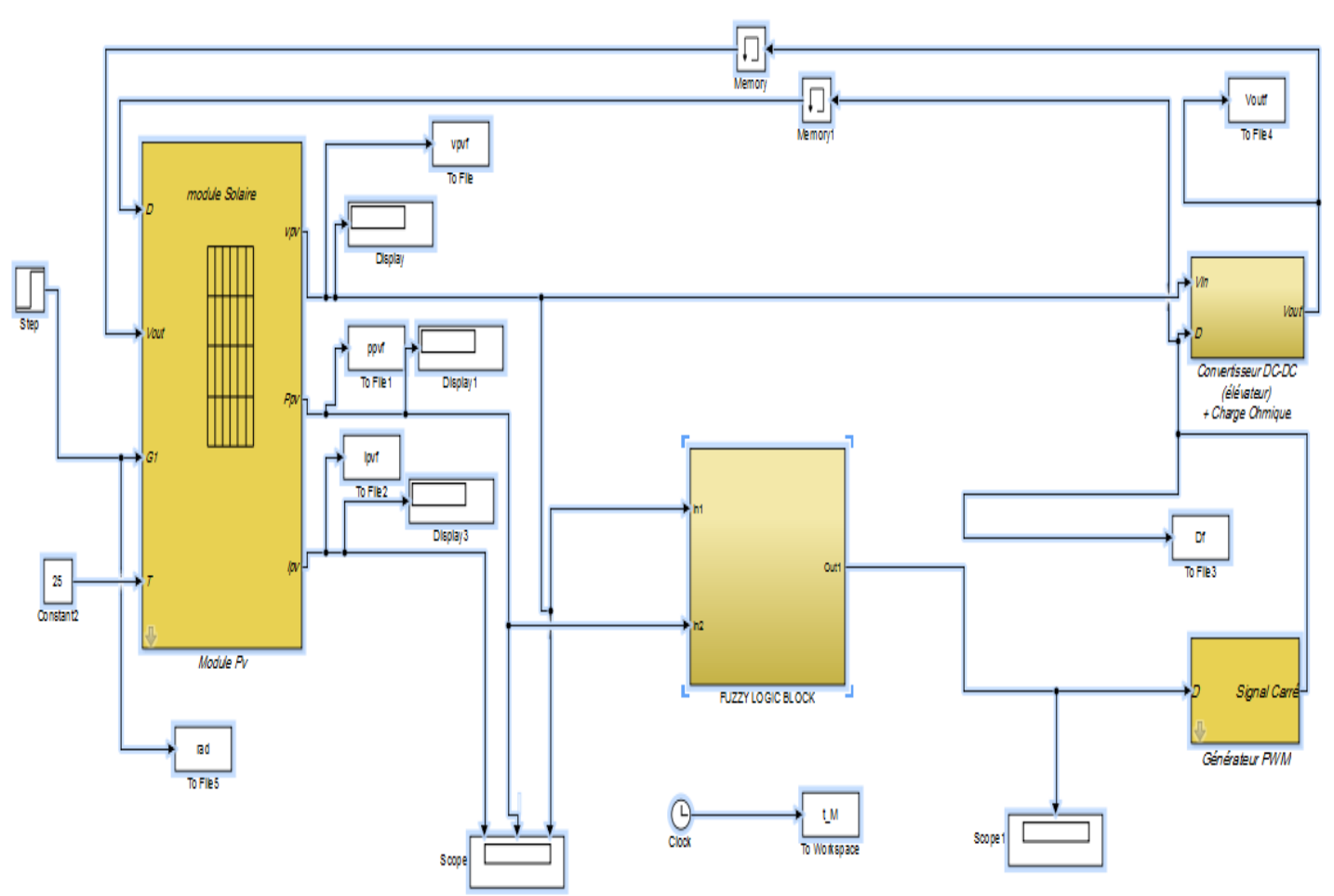

Figure 7. Layout of the simulated system

\subsection{MPPT based on $P \& O$ algorithm results}

On Figure 8 the obtained results of the P\&O algorithm show that the PV voltage is equal to $34 \mathrm{~V}$ and the output power on Figure 8 (c) presents a small overshoot.

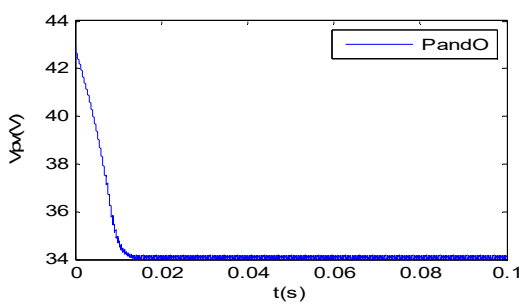

(a)

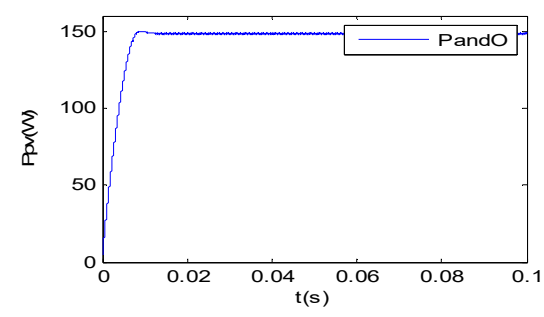

(c)

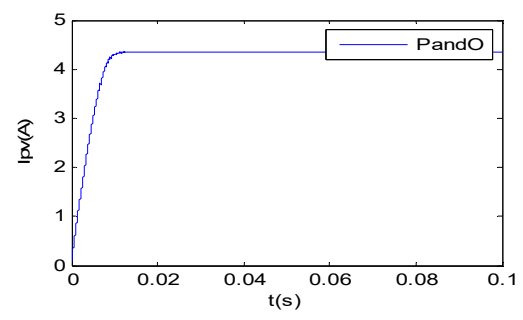

(b)

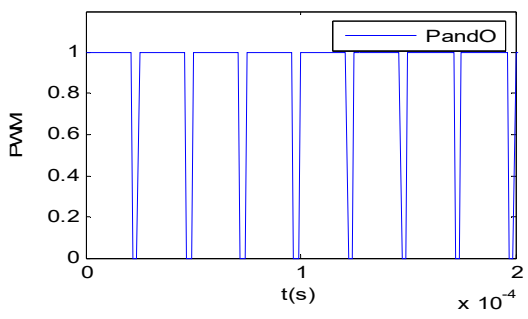

(d)

Figure 8. P\&O algorithm results: (a) PV's voltage, (b) PV's current, (c) PV's power, (d) PWM signal 


\subsection{Fuzzy MPPT based on mamdani's inference results}

Mamdani's inference results are depicted on Figure 9. We can notice that the output power is nearly without overshoot and the PV voltage presents a small undershoot.

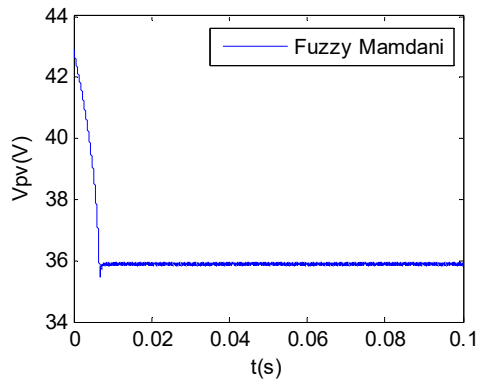

(a)

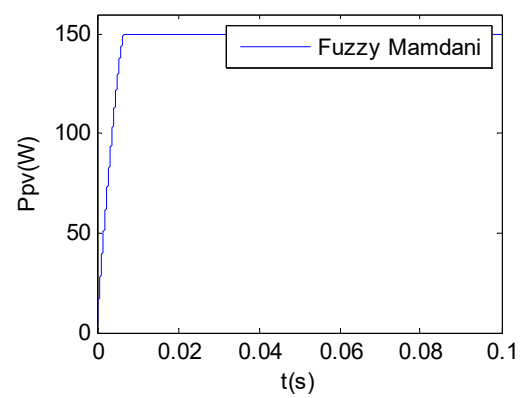

(c)

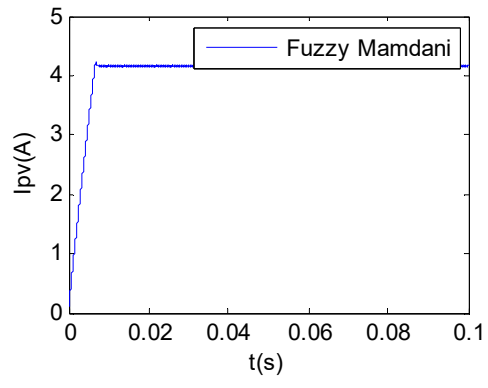

(b)

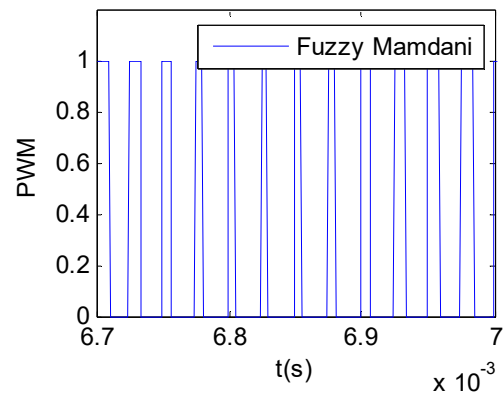

(d)

Figure 9. Mamdan's inference results: a) PV's voltage, b) PV's current, c) PV's power, d) PWM signal

\subsection{Fuzzy MPPT based on sugeno's inference results}

Compared to above results, the output power obtained using sugeno's inference Figure 10 (c) is without overshoot and the PWM signal Figure 10 (d) shows the efficiency of this method.

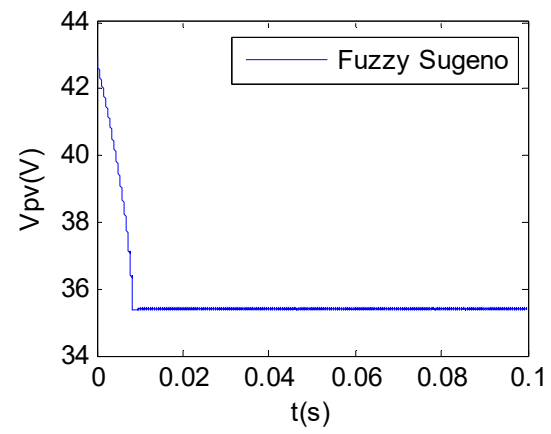

(a)

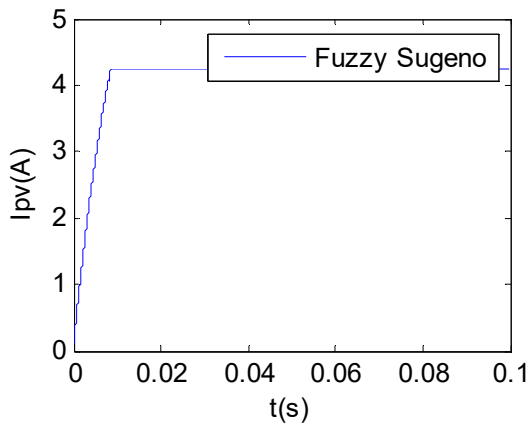

(b) 


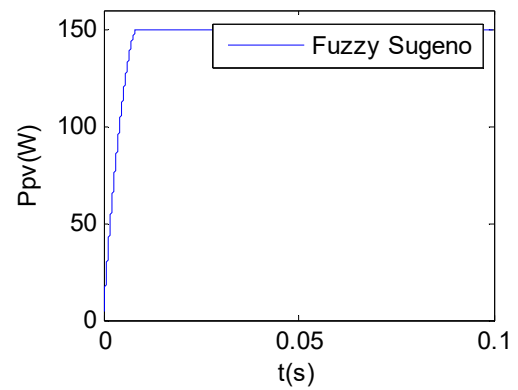

(c)

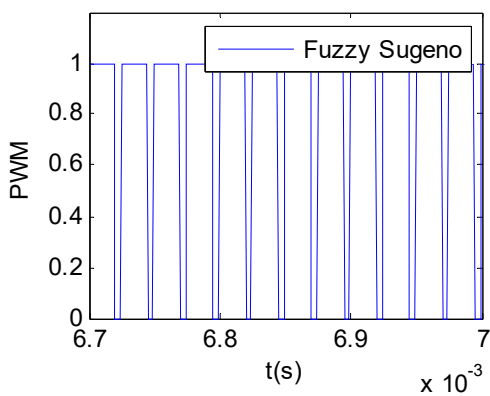

(d)

Figure 10. Sugeno's inference results: (a) PV's voltage, (b) PV's current, (c) PV's power, (d) PWM signal

The comparison of the PV's powers is presented on Figure 11. On Figure 11 (a) we can notice through the zoom that the MPPT based on Sugeno's inference delivers a maximum power in steady state zone and the intelligent controllers are more performance than the conventional controller based on P\&O algorithm.

The Table 4 shows the numerical values of the PV power for each strategy.

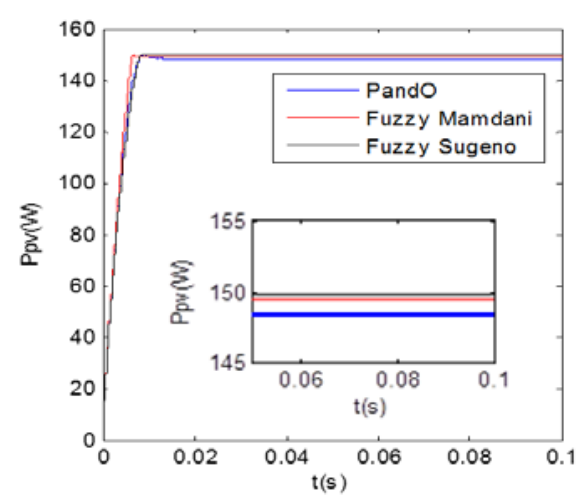

(a)

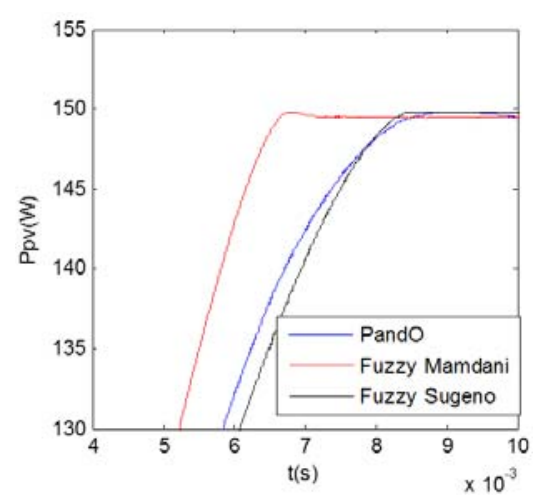

(b)

Figure 11. (a) PV's powers for each method, (b) zoom of PV's powers

Table 4. Numerical values of controllers' performances

\begin{tabular}{cccc}
\hline & P\&O algorithm & Mamdani's inference & Sugeno's inference \\
\hline RiseTime (s) & 0.0056 & 0.0050 & 0.0050 \\
SettlingTime (s) & 0.0075 & 0.0063 & 0.0064 \\
SettlingMin (W) & 134.0605 & 134.9513 & 135.2711 \\
SettlingMax (W) & 149.8105 & 149.7950 & 149.8105 \\
Overshoot & 0.9057 & 0.2234 & 0.0003 \\
Undershoot & 0 & 0 & 0 \\
Peak (W) & 149.8105 & 149.7650 & 149.8105 \\
PeakTime (s) & 0.0092 & 0.0068 & 0.0293 \\
\hline
\end{tabular}

\section{LOAD CHANG}

We have increased the load up to $50 \%$ to evaluate the robustness of each strategy. The obtained results according to Figure 12 (a) and (b) show that FLCs are more robust than the P\&O algorithm because at $0.05 \mathrm{~s}$ when the system is loaded, they are more stable than $\mathrm{P} \& \mathrm{O}$ algorithm. 


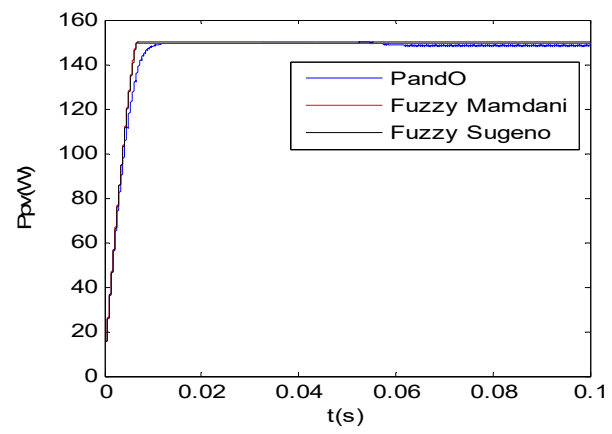

(a)

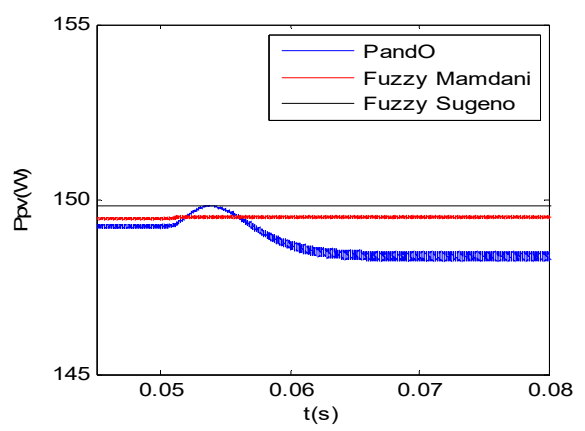

(b)

Figure 12. load change results: (a) PV's powers for each method, (b) zoom of PV's powers

\section{CONCLUSION}

The PV array has a maximum power point (MPP) which varies with the change of solar irradiation and cell temperature. The controllers by fuzzy logic can provide more effective response than the traditional controller for the nonlinear systems, because there is more flexibility. They are robust and MPP was obtained in shorter time runs as is shown on Table 4. The FLC based on Sugeno's inference presents certain performances compared to Mamdani's inference in terms of settling max, overshoot and peak value.

\section{REFERENCE}

[1] T. Esram and P. L. Chapman, "Comparison of photovoltaic array maximum power point tracking techniques," IEEE Transactions on Energy Conversion 22 (2); pp. 439-449, 2007.

[2] F. Dincer and M. E. Meral, "Critical factors that affecting efficiency of solar cells," Smart Grid and Renewable Energy 1 (1), pp. 47-50, 2010.

[3] G. Graditi, G. Adinolfi, and G. M. Tina, "Photovoltaic optimizer boost converters: Temperature influence and electro-thermal design," Applied Energy 115 (c), 140-150, 2014.

[4] Gudimetla Ramesh, Kari Vasavi, and S. Lakshmi Sirisha, "Photovoltaic Cell Fed 3-Phase Induction Motor Using MPPT Technique", International Journal of Power Electronics and Drive System (IJPEDS), Vol. 5, No. 2, pp. 203-210, October 2014.

[5] Guruswamy Revana, and Venkata Reddy Kota, "Modeling and Fuzzy Logic Control of PV Based Cascaded Boost Converter Three Phase Five-level Inverter System", International Journal of Power Electronics and Drive System (IJPEDS), Vol. 8, No. 3, pp. 1389-1400, September 2017.

[6] Taoufik Laagoubi, Mostafa Bouzi, and Mohamed Benchagra, "MPPT \& Power Factor Control for Grid Connected PV Systems with Fuzzy Logic Controllers", International Journal of Power Electronics and Drive System (IJPEDS) Vol. 9, No. 1, pp. 105-113, March 2018.

[7] E. Irmak and N. Güler, "Application of a high efficient voltage regulation system with MPPT algorithm", Electrical Power and Energy Systems 44 (1), pp. 703-712, 2013.

[8] B. B. J. D. Retnam and A. Gounden, "Power Electronic Interface with Maximum Power Point Tracking Using Line-commutated Inverter for Grid-connected Permanent Magnet Synchronous Generator", Electric Power Components and Systems 43 (5), pp. 543-555, 2015.

[9] V. Salas, E. Olias, A. Barrado, and A. Lazaro, "Review of the maximum power point tracking algorithms for standalone photovoltaic systems", Solar Energy Materials and Solar Cells 90 (11), 1555-1578, 2006.

[10] D. Mi, Y. Jian, and P. Ke, "Zero average incremental conductance maximum power point tracking control for photovoltaic system”, Proc CSEE 30, pp. 48-53, 2010,

[11] F. Liu, S. Duan, F. Liu, B. Liu, and Y. Kang, "A Variable Step Size INC MPPT Method for PV Systems", IEEE Transactions on Industrial Electronics 55 (7),pp. 2622-2628, 2008.

[12] B. N. Alajmi, K. H. Ahmed, S. J. Finney, and B. W. Williams, "FuzzyLogic Control Approach of a Modified HillClimbing Method for Maximum Power Point in Microgrid Standalone Photovoltaic System," IEEE Trans on, Power Electronics, vol. 26, No. 4, pp. 1022-1030, 2011.

[13] V. Quaschning, "Renewable Energy and Climate Change. 1st ed", John Wiley \& Sons, Chichester, West Sussex, United Kingdom, 2010.

[14] F. Kininger, "Photovoltaic Systems Technology. 1st ed", Universität Kassel, Wil-helmshöher Alle 73, 34121 Kassel, Germany, 2003.

[15] S. J. E. Mineiro, S. Daher, F. L. M. Antunes, and C. M. T. Cruz, "Photovoltaic system for supply public illumination in electrical energy demand peak", IEEE Conference on applied power electronics conference and exposition.Fortaleza, Brazil: IEEE Pres, pp. 1501- 1506, 2004. 
[16] S. Saravanan and Ramesh Babu N, "Maximum power point tracking algorithms for photovoltaic system -A review", Renewable and Sustainable Energy Reviews 57, pp.192-204, 2016.

[17] N. Patcharaprakitia, et al. "Maximum power point tracking using adaptive fuzzy logic control for grid-connected photovoltaic system", in IEEE Power Eng. Society Winter Meeting, pp. 372-377, 2002.

\section{BIOGRAPHIES OF AUTHORS}

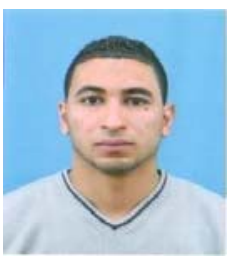

Mohammed Slimi was born in Bechar, Algeria, in 1990. He received his license degree and Master degree in electrical engineering from the Electrical Engineering Institute of the University of Bechar in 2011 and 2013, respectively.Currently he is member of the Research Laboratory of Control Analysis and Optimization of the Electro-Energetic Systems.

His research interests are automatic control, artificial intelligence and renewable energy. e-email : mohammed.slimi213@gmail.com

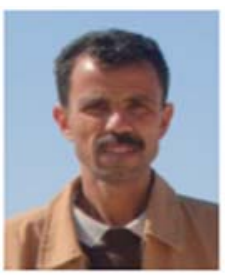

Abdelkrim Boucheta Was born in Bechar, Algeria, in 1971. He received his BS degree and M.S. degree in electrical engineering from the Electrical Engineering Institute of the University Center of Bechar, in 2001 and 2006, respectively

He received the $\mathrm{PhD}$ degree in Electrical Engineering from the University of Djilali Liabes SidiBelabbes (Algeria), in 2010, He is currently Professor of electrical engineering at University of Bechar, His areas of interest are modern and adaptive control and their application in linear electric drives control.

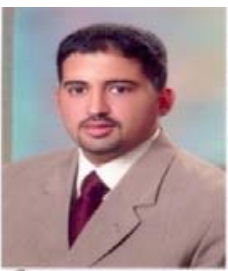

Bousmaha Bouchiba was born in 1977 at Bechar-Algeria, he's received the electrical engineering diploma from Bechar University,-Algeria in 1999, and the Master degree from the University Alexandria Egypt in 2006 and the Ph.D. degree from the Electrical Engineering Institute of the SDB in 2011. Currently, he is an assistant professor at Bechar University.where he is member of the Research Laboratory of Control Analysis and Optimization of the ElectroEnergetic Systems. His research interests include power electronics, electric drives control, and artificial intelligence and their applications. 